\title{
Inovação em produtos agroalimentares: uma avaliação das mudanças qualitativas no suíno utilizando conjuntos fuzzy ${ }^{1}$
}

Júlio Eduardo Rohenkohl²

Orlando Martinelli ${ }^{3}$

Rosângela Ballini ${ }^{4}$

Resumo: Utilizando-se da teoria dos conjuntos fuzzy, este artigo analisa a mudança no tempo da produtividade nos porcos e de qualidade da carne na sua carcaça, bem como identifica as alterações nos referenciais de avaliação de produtividade e de qualidade desses produtos. Considera-se que a inovação tecnológica não é aleatória, mas atrelada aos trade-offs das trajetórias tecnológicas em curso na genética suína e nos demais componentes do sistema tecnológico de carne suína.

Palavras-chave: inovação; qualidade; conjuntos fuzzy; suínos.

\section{Innovation on agri-food products: an evaluation of the qualitative changes on swine using fuzzy sets}

\footnotetext{
Abstract: Using fuzzy sets theory, this article aims at analyzing the change on swine productivity and on quality of the pork in its carcass as time passes, as well as identifies changes in the evaluative referential of productivity and quality of these products. The belief is that the technological innovations is not infinite or random but, it is linked to the trade-offs in technological procedures followed in the swine genetics and in the other components of the pork technological system.

1 Agradecemos os comentários dos avaliadores e o apoio da CAPES e do Diretório da Pesquisa Privada - Convênio Finep/Fundunesp.

2 Departamento de Ciências Econômicas da Universidade Federal de Santa Maria. E-mail: julioroh@gmail.com.

3 Departamento de Ciências Econômicas da Universidade Federal de Santa Maria. E-mail: martinelli@smail.ufsm.br.

4 Instituto de Economia da Universidade Estadual de Campinas. E-mail: ballini@eco.unicamp.br.
} 
ROHENKOHL, J. \& MARTINELLI, O. \& BALLINI, R. Inovação em produtos agroalimentares...

Keywords: innovation; quality; fuzzy sets; swine.

JEL: O12, O33.

\section{Introdução}

A dinâmica tecnológica em setores agroindustriais apresenta dimensões econômicas, sociais e institucionais complexas e interdependentes. O curso da inovação e de sua difusão no mercado não é necessariamente linear, e perpassa diversos ambientes e planos seletivos. Embora esses fatores possam ser diferenciados entre setores (ou segmentos) produtivos agroalimentares, pelo menos duas características são comuns. A primeira é o grau de incerteza quanto aos resultados econômicos decorrentes de atributos diferenciadores dos produtos para os quais há dificuldade de avaliação perfeita a priori. A percepção dos novos atributos advindos da inovação é associada a aspectos cognitivos e subjetivos dos produtores e dos consumidores, cujos limites são históricos e inerentemente vinculados a valores sócio-culturais, a aspectos institucionais normativos formais (e.g. a evolução da legislação sobre práticas sanitárias) e/ou informais (e.g. o padrão de consumo ao longo do tempo).

A segunda característica é que a busca da inovação não é aleatória. Os novos produtos que chegam aos mercados estão atrelados ao path dependence setorial das trajetórias tecnológicas e das características institucionais do mercado. A partir de um conjunto mais amplo de possibilidades técnicas, há um processo de seleção e afunilamento das possibilidades tecnológicas utilizadas por um setor ou segmento econômico que se transforma em oportunidades efetivas de negócios, filtradas pelos aspectos econômicos e sócio-culturais do mercado.

Esses aspectos econômicos, tecnológicos e sócio-institucionais peculiares fazem com que as inovações em setores agroalimentares sejam, em sua grande maioria, incrementais. Ao mesmo tempo, a natureza sistêmica da inovação e a incorporação de tecnologias genéricas nesses setores têm induzido a um movimento de "decommoditização" e de mudanças qualitativas nos produtos agroalimentares (Pessanha \& Wilkinson 2003; Eymard-Duvernay 1989, 1995; Chevassus-Lozza \& Gallezot 1995; Andersen 2000). Este movimento é o resultado não apenas da agregação de novas etapas ou da segmentação de etapas produtivas de transformação industrial do produto primário - ou artefato básico -, mas especialmente da própria diferenciação qualitativa do produto primário. Esta, por sua vez, está diretamente atrelada à dinâmica evolutiva do Sistema Tecnológico (ST) setorial específico. 
Neste contexto complexo, o desafio analítico é a construção de modelos empíricos que possam captar e ordenar a transformação simultânea dos aspectos de produtividade e de qualidade no tempo - seja em relação à sua evolução passada, como a de projeções futuras -, simplificando minimamente as condições ambientais de análise e/ou as possibilidades de variação comportamental dos agentes e/ou de configuração do ST.

O objetivo principal deste artigo é, portanto, a construção e análise de indicadores que possam contribuir para a inferência das mudanças tecnológicas em curso nos produtos agroalimentares, analisando o caso do "artefato porco" (porco-animal) e da carne em sua carcaça. Nesse propósito, recorre-se à teoria dos conjuntos fuzzy, que possibilita o uso de um "modelo de especialistas" para construir e hierarquizar indicadores que captem a transformação de produtividade e mudanças em atributos de qualidade nesses produtos. Foram elaborados indicadores sobre: a) a qualidade da carcaça (QC) do porco-animal, considerando dois atributos, quais sejam a "espessura do toucinho" (ET) e o "percentual de carne na carcaça" (\% carne); b) a produtividade do porco-animal, considerando dois atributos, a prolificidade em termos de "leitões nascidos por parto" (LP), e a "conversão alimentar" (CA); e c) a qualidade da carne, conjunto resultante da intersecção entre, de um lado, uma classificação que contempla a cor, a maciez e a capacidade de retenção de água e, de outro, o Limite Máximo de Resíduos (LMR) na carne. Além disso, fez-se um exercício ilustrativo-metodológico de projeção futura de indicadores (CA, LP, ET e \% de carne), por meio da construção de um índice fuzzy de adequação ao esperado desses itens para o ano de 2010.

O artigo está estruturado da seguinte forma: na próxima seção são apresentadas algumas noções derivadas da abordagem schumpeteriana e que alicerçam teoricamente a argumentação. A seguir, são discutidos alguns pontos da teoria dos conjuntos fuzzy e descritos os procedimentos metodológicos empreendidos para a construção do "modelo de especialistas" e dos indicadores; são ainda apresentados os resultados do processo de inferência do modelo. Por fim, a última parte traz as conclusões.

\section{O estreitamento do campo de possibilidades}

Um paradigma tecnológico é a definição de problemas relevantes a serem resolvidos com um corpo específico de conhecimento. O paradigma fornece a amplitude, o horizonte das possibilidades de inovação em processos produtivos e em produtos. A trajetória tecnológica pode ser definida como o incremento em trade-offs técnicos e econômicos, como o 
processo de escolhas econômicas e técnicas dentre as possibilidades de um paradigma tecnológico.

O sistema tecnológico (ST) é definido como uma rede dinâmica de agentes interagindo em uma área industrial específica, sob uma infra-estrutura institucional particular e dedicada à geração, difusão e utilização de tecnologia. Esses sistemas são delineados em termos de fluxos de conhecimento e competência em lugar dos tradicionais fluxos de bens e serviços (Carlsson \& Stankiewicz 1991; Carlsson \& Eliasson 2003).

Neste trabalho, estudam-se dois produtos inter-relacionados física e biologicamente, o suíno e a sua carcaça/carne, submetidos ao mesmo ambiente de seleção (Figura 1). Identificam-se as tecnologias genéricas compostas para a sua produção e os agentes que se relacionam para tanto.

Os agentes que participam do ST em questão (Figura 2) são as universidades, os centros de pesquisa (criadores de conhecimento aplicado e testadores de produto), os insumidores dos grupos de desenvolvimento genético, medicamentos/aditivos e nutrição - geradores de produtos que inovam o artefato "o animal" - os criadores independentes e as firmas integradoras/abatedoras de animais. Eles relacionam-se por meio da troca de informações técnicas e/ou de produtos, ou do compartilhamento de conhecimento, conforme as suas competências. Os componentes de um ST contribuem para a identificação de possibilidades técnicas aplicadas a serem convertidas em oportunidades de negócio em interação com o mercado.

As relações entre os componentes do sistema são conformadas por instituições próprias ao ST. Estas relações compreendem a legislação de propriedade intelectual, o paradigma tecnológico e o sistema de educação que forma os recursos humanos.

O ST possui uma dimensão cognitiva que define dentro de um conjunto maior de possibilidades técnicas - chamado de espaço de estado , um reduzido recorte de possibilidades tecnológicas, e o espaço de desenho, efetivamente utilizado para a criação de inovações pelo setor ou segmento. O espaço de desenho agrega todo o conhecimento relevante contido nas pessoas e nas organizações e é utilizado em uma atividade econômica inovativa. Logo, ele se transforma a partir de novo conhecimento. Apenas uma parte das possibilidades do espaço de desenho transforma-se em oportunidades de negócios (Carlsson \& Eliasson 2003). Quanto maior for a capacidade dos agentes no sistema de receber e de absorver conhecimento técnico, maiores as chances de que oportunidades de negócio sejam identificadas (Carlsson \& Eliasson 2003). 
ROHENKOHL, J. \& MARTINELLI, O. \& BALLINI, R. Inovação em produtos agroalimentares...

FIGURA 1- SISTEMA TECNOLÓGICO CARACTERIZADO PELOS PRODUTOS

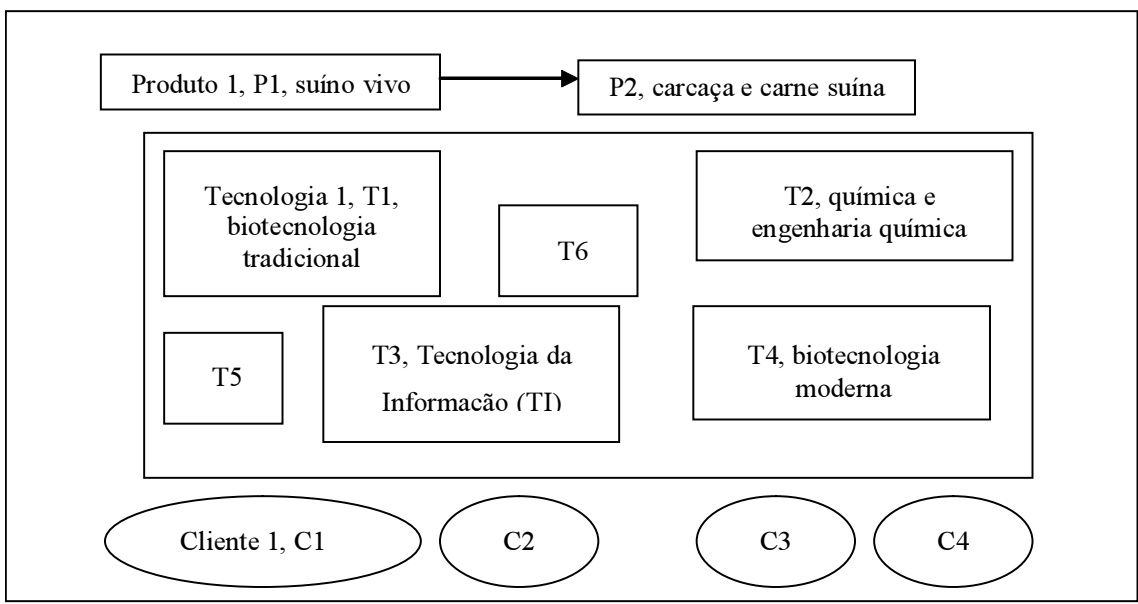

Mudanças radicais na base de conhecimento podem originar outros espaços de desenho e o ST acaba criando conhecimento aplicado alicerçado em mais de uma tecnologia. Um exemplo aplicado à realidade agroindustrial está relacionado à genética suína. Seu espaço de desenho, até os anos de 1980, era limitado à genética quantitativa, delimitação aplicada de um paradigma que combinava biotecnologia tradicional (inseminação artificial) com softwares estatísticos para estimativa de desempenho dos animais. A ampliação do paradigma tecnológico (setorial) com a incorporação da biotecnologia moderna originou no espaço de desenho uma expansão correspondente com a incorporação da investigação genômica.

Também compatível com este novo paradigma é a perspectiva de ampliação do espaço de desenho pelo uso futuro da transgenia aplicada à seleção de animais. Os contornos do ST não são fixos e a sua transformação é alicerçada em nova base de conhecimento multifacetada (formada por tecnologias genéricas compostas) que altera o(s) espaço(s) de desenho, provoca transformações nos produtos para cuja produção contribui com conhecimento aplicado. Com isto, muda o "menu" de produtos a serem selecionados no mercado. O produto é a composição de diversas tecnologias genéricas aplicadas a um setor/segmento. 
FIGURA 2- SISTEMA TECNOLÓGICO DE CARNE SUÍNA

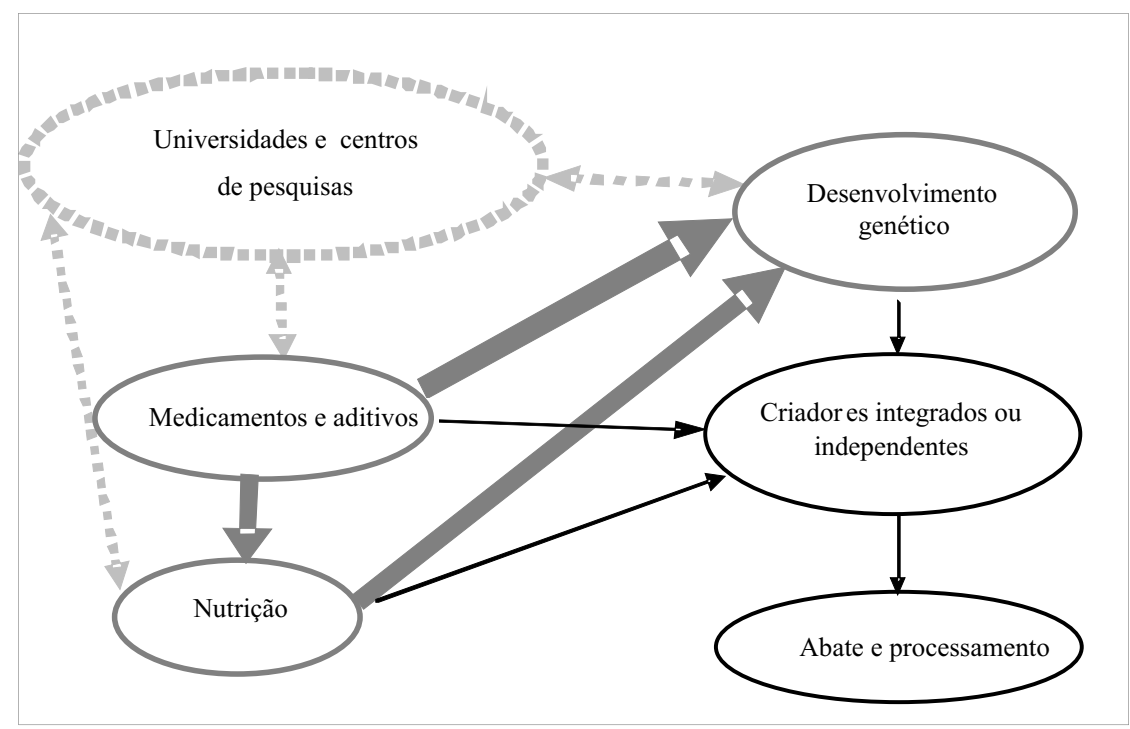

Legenda:

Compartilhamento de conhecimento:

Fluxo de produto e de informações técnicas entre insumidores:

Fluxo de produto e informações técnicas para a criação e abate:

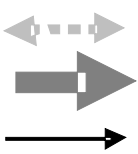

A Figura 3 sintetiza o afunilamento das possibilidades técnicas até que sejam identificadas as oportunidades de negócios junto ao mercado. Partindo do espaço de estado com todas as combinações técnicas possíveis relacionadas com o grupo industrial - e percebido como opaco e de dimensões incertas pelos agentes -, há uma primeira delimitação com o paradigma tecnológico utilizado no grupo de genética. Aí aparecem as tecnologias genéricas, que combinadas geram a lógica de solução de problemas, onde e como buscar as soluções, reduzindo o espaço de busca. O espaço de desenho é outro passo deste afunilamento e identifica um conjunto de possibilidades técnicas utilizado pela rede de agentes do Sistema Tecnológico (ST). Nele, o conhecimento das pessoas e das organizações, especializadas em algumas ramificações das tecnologias genéricas, é aplicado para operacionalizar a lógica do paradigma. É definida uma delimitação mais precisa das possibilidades técnicas a serem exploradas em um período. Destas, algumas efetivamente são trilhadas nas trajetórias tecnológicas e originam oportunidades de negócios.

Considerando como estável o ambiente institucional a envolver as opções de inovação de produto, ouvir os especialistas responsáveis por incrementos na qualidade dos animais permite inferir a respeito das 
alterações de qualidade em curso e, inclusive, projetar perspectivas futuras. Eles conhecem as possibilidades de diferenciação qualitativa e de incremento de produtividade que estão sendo exploradas e possuem uma idéia aproximada do resultado das pesquisas ou do desenvolvimento de produtos e processos em curso.

FIGURA 3- AFUNILAMENTO DAS POSSIBILIDADES INOVATIVAS

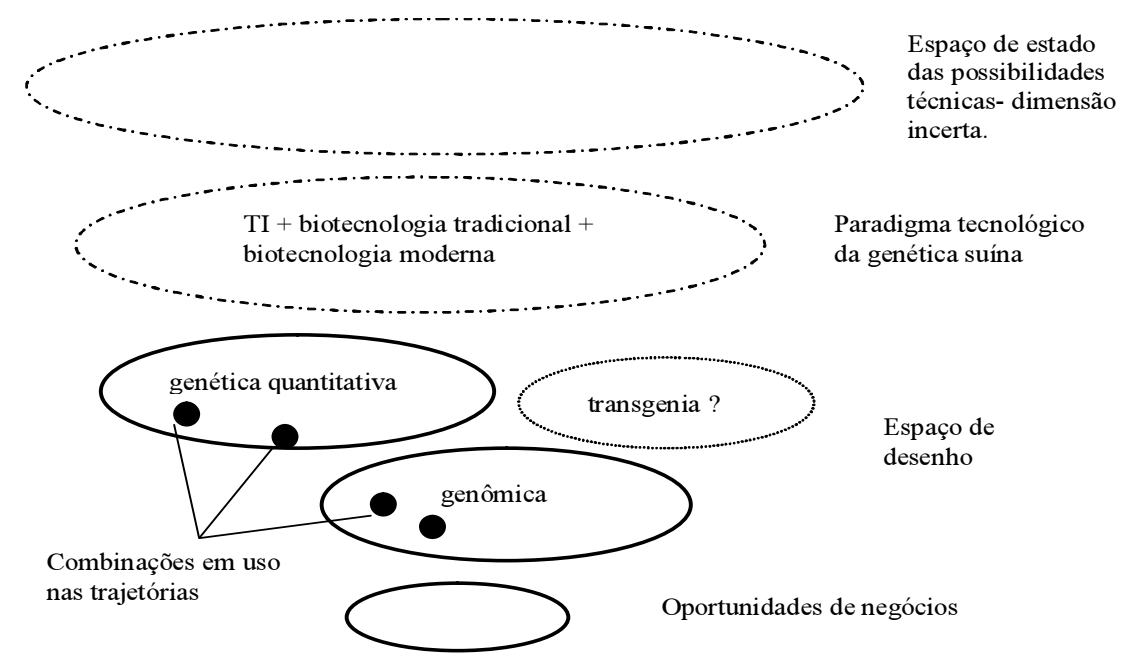

\section{Procedimentos metodológicos e resultados 2.1 Os conjuntos fuzzy}

A lógica fuzzy estende os conceitos da lógica booleana clássica para os números reais. Ao contrário da lógica clássica, que tem somente dois valores, verdadeiro ou falso, a lógica fuzzy é multivalorada, sendo os valores representados por conjuntos fuzzy. Em essência, o que a lógica fuzzy oferece é uma ferramenta para tratar palavras ao invés de números, o que nenhum outro método faz.

A teoria dos conjuntos fuzzy permite lidar com problemas em que a imprecisão não resulta do comportamento aleatório das variáveis, mas da ausência de critérios claramente definidos de pertinência (de uma observação ou indivíduo) a um determinado conjunto. As variáveis lingüísticas (palavras ou sentenças) podem assumir valores, cujos graus de precisão não podem ser mensurados com certeza. 
Um conjunto fuzzy é definido matematicamente por meio da atribuição de um valor que representa o grau de pertinência ao conjunto de cada indivíduo no universo. Este grau de pertinência representa a semelhança deste indivíduo ao significado que dá identidade ao conjunto. Em termos formais tem-se: Um conjunto fuzzy $A$ é caracterizado por uma função de pertinência $\mu_{A}(x)$, a qual associa a cada elemento de um domínio, espaço ou um universo de discurso $X$, um número real no intervalo unitário $[0,1]$. O valor de $\mu_{A}(x)$ em $X$ representa o grau de pertinência de $x$ em $A$ (Zadeh 1965). Um conjunto fuzzy representa uma coleção de objetos com valores associados entre o (exclusão completa) e 1 (associação completa). Os valores associados expressam o grau com o qual cada objeto é compatível com as características ou propriedades que são distintas para a coleção.

As funções de pertinência associadas aos conjuntos fuzzy dependem não somente do conceito a ser representado, mas também do contexto no qual são usadas. As funções podem ter diferentes formas e algumas propriedades, tal como continuidade, podem ser exigidas (Pedrycz \& Gomide 1998). A função de pertinência mais empregada é a triangular, descrita como segue:

$$
\mu_{A}(x)=\left\{\begin{array}{lr}
0, & x \leq \rho_{\min } \\
\frac{x-\rho_{\min }}{c-\rho_{\min }} & , x \in\left(\rho_{\min }, c\right] \\
\frac{\rho_{\max }-x}{\rho_{\max }-c} & x \in\left(c, \rho_{\max }\right] \\
0, & x \rho_{\max }
\end{array}\right.
$$

sendo $\rho_{\min }$ e $\rho_{\max }$ os valores de dispersão mínimo e máximo, respectivamente, e o parâmetro $c$ o centro ou valor modal da função.

Como as funções de pertinência são representações equivalentes dos conjuntos fuzzy, as operações básicas de interseção, união e complemento são representadas tomando o mínimo, máximo e complemento das correspondentes funções características. Estas operações são chamadas operações fuzzy padrões.

Na teoria de conjuntos fuzzy, as normas triangulares têm um papel fundamental para fornecer os modelos genéricos para as operações de interseção e união, devendo possuir as propriedades de comutatividade, 
associatividade e monotonicidade e satisfazer as condições de contorno. Portanto, as normas triangulares formam classes gerais de interseção e união respectivamente caracterizadas pelas chamadas normas e co-normas. As normas fuzzy são também chamadas de t-normas e as conormas de s-normas.

Levando em conta as propriedades das normas triangulares, o operador min é uma t-norma e o operador max é uma s-norma. Logo, as operações sobre conjuntos fuzzy podem ser interpretadas como conectivos lógicos e as t-normas e s-normas podem ser identificadas como conectivos lógicos conjuntivos (E) e disjuntivos (OU), respectivamente.

Desta forma, a interseção de dois conjuntos fuzzy, $A$ e $B$, representada por $A$ Ç $B$, define o maior conjunto fuzzy que contenha $A$ e $B$. A função de pertinência de $A$ Ç $B$ é dada por $\mu_{(A \zeta B)}(x)=\min \left(\mu_{A}(x), \mu_{B}(x)\right)$, sendo min o mínimo entre os graus de pertinência.

A união de dois conjuntos $A$ e $B$ é representada por $A$ È $B$, definindo o menor conjunto fuzzy que contenha $A$ e $B$. A função de pertinência é dada por $\mu_{(A \grave{\mathrm{E}} B)}(x)=\max \left(\mu_{A}(x), \mu_{B}(x)\right)$, sendo max o máximo entre os graus de pertinência.

Com a definição dos conjuntos fuzzy, das variáveis associadas a esses conjuntos e das normas e conormas, pode-se construir regras fuzzy do tipo Se <antecedente $>$ Então <conseqüente $>$ para que, a partir de um mecanismo de inferência fuzzy, seja possível obter conclusões para fatos a partir de uma base de regras. Assim, a base de regras é constituída de $M$ regras do tipo:

$$
R^{(t)}: \text { Se } x_{1} \in A_{1} E x_{2} \in A_{2} \ldots x_{N} \in A_{N} \text { Então yé } g^{l}
$$

sendo $\boldsymbol{l}=\mathbf{1}, \mathbf{2}, \ldots, \boldsymbol{M} ; \boldsymbol{x}_{\boldsymbol{i}}, \boldsymbol{i}=\mathbf{1}, \ldots, \boldsymbol{N}$, as variáveis associadas aos conjuntos fuzzy $\boldsymbol{A}_{\boldsymbol{i}}$; e $\boldsymbol{y}$ a saída dada por uma função $\boldsymbol{g}^{\boldsymbol{l}}$ que depende das variáveis de entrada e dos graus de pertinência associados aos conjuntos fuzzy.

A inferência das $M$ regras fuzzy ativas para um determinado vetor de entrada $\mathrm{x}=\left[\boldsymbol{x}_{\mathbf{1}}, \boldsymbol{x}_{2}, \ldots, \boldsymbol{x}_{N}\right]$, que é composto por $N$ variáveis $\boldsymbol{x}_{\boldsymbol{i}}$, tem como objetivo fornecer a saída do sistema fuzzy. Esta saída é calculada por meio de um mecanismo de defuzzyficação.

Existem vários métodos de calcular a saída do sistema fuzzy (Pedrycz \& Gomide 1998). Neste artigo, utilizou-se o mecanismo de defuzzyficação dado pelo método do centro de gravidade (Pedrycz \& Gomide 1998; Bojadziev \& Bojadziev 1995), dado por: 


$$
\mathrm{CG}=\frac{\sum_{\mathrm{j}=1}^{\mathrm{N}} \mathrm{x}_{\mathrm{j}} \mu_{\mathrm{j}}}{\sum_{\mathrm{j}=1}^{\mathrm{N}} \mu_{\mathrm{j}}}
$$

sendo $\mu_{j}$ o grau de pertinência da variável $x_{j}$ no conjunto fuzzy $A_{j}$.

Com base na teoria dos conjuntos fuzzy, neste artigo são propostos indicadores para analisar: a) a qualidade da carcaça (QC); b) a produtividade do porco-animal; e, c) qualidade da carne. Além disso, por meio da construção de um índice fuzzy de adequação, fez-se uma projeção deste índice para o ano de 2010. A seguir, cada um dos indicadores é apresentado.

\subsection{Indicadores fuzzy de mudanças no produto}

A construção dos indicadores sobre as mudanças de produtividade do "artefato porco" (o porco-animal) e de qualidade da carne em sua carcaça baseou-se em duas hipóteses. A primeira é que o espectro de inovação tecnológica apresenta trade-offs importantes no âmbito das possibilidades técnicas de inovação do paradigma tecnológico dominante na genética suína. A segunda hipótese é da perenidade dos demais elementos que compõem o ST da carne suína. Essas hipóteses não congelam as condições tecnológicas do ST, mas, diferentemente, sinalizam que o processo inovativo não é aleatório nem infinito. Ou seja, considera-se que a evolução tecnológica é path dependent das configurações da "trajetória natural" existentes no ST, descartando assim rupturas radicais no período (Dosi 1982; Nelson \& Winter 1977).

Com base nessas hipóteses foram construídos três blocos de indicadores específicos, trilhando os passos metodológicos seguintes . Em primeiro lugar foram coletados dados de referência para alguns indicadores $^{5}$ e sobre o "estado das artes" na genética suína em trabalho da Empresa Brasileira de Pesquisa Agropecuária (Fávero \& Guidoni 2001) e nos registros da Associação Brasileira de Criadores de Suínos (ABCS).

A partir desses dados de referência, elaborou-se um questionário (semiestruturado) aplicado a quatro especialistas em suínos. Dois são cientistas da área de suínos em uma Universidade Federal brasileira e os outros dois são pesquisadores de uma firma de genética suína e

\footnotetext{
5 Esses valores foram indicados por RF nas tabelas e se referem às variáveis "espessura do toucinho"; "percentual de carne"; prolificidade em termos de "leitões nascidos por parto"; "conversão alimentar"; cor, maciez e capacidade de retenção de água; e Limite Máximo de Resíduos.
} 
processamento de carne. Efetuaram-se questões abertas sobre a pesquisa aplicada e o desenvolvimento dos insumos para a criação de suínos no Brasil seguidas por outras, fechadas, para a confecção do modelo fuzzy.

Os especialistas, considerando o estado da técnica atual (ano 2005) e dados de referência dos anos de 1985, 1995 e 2004, opinaram sobre: a) a qualidade da carcaça (QC) do porco-animal, considerando dois atributos, quais sejam a "espessura do toucinho" (ET) e o "percentual de carne" na carcaça (\% carne); b) a produtividade do porco-animal, considerando dois atributos, a prolificidade em termos de "leitões nascidos por parto" (LP), e a "conversão alimentar" (CA); e c) a qualidade da carne, considerando a cor, a maciez e a capacidade de retenção de água, e o Limite Máximo de Resíduos (LMR) ${ }^{6}$.

O terceiro passo foi a construção do modelo especialista (sistema fuzzy), a partir da elaboração dos termos lingüísticos, das bases de regras para o processo de inferência e do procedimento de defuzzyficação. Na construção dos conjuntos utilizou-se: a) a medida das variáveis conseqüentes, ou seja, a qualidade da carcaça, a produtividade e a qualidade da carne, variando entre o e 1 (eixo horizontal); b) conjuntos fuzzy triangulares centralizados, representados por funções de pertinência triangulares dadas pela Equação (1).

Para definir os conjuntos fuzzy, ou seja, os valores modais e as dispersões relacionadas a cada função de pertinência, cada especialista atribuiu o valor da variável base que o deixaria em dúvida para uma classificação, como, por exemplo, de percentual de carne "bom" ou "médio". $\mathrm{O}$ valor respondido foi interpretado como de pertinência 0,5 aos valores lingüísticos "bom" e "médio" relativos à variável em questão (\% de carne). Ao repetir o procedimento e obter outro valor de ambivalência entre o conjunto "médio" e o "ruim", projeta-se o ponto de pertinência 1 ao conjunto "médio" a partir das duas pertinências 0,5 aos segmentos ascendentes e descendentes da função de pertinência.

A Figura 4 ilustra os conjuntos fuzzy que representam os termos linguíisticos "muito ruim", "ruim", "médio" e "bom" relacionados à variável percentual de carne. Da mesma forma, foram construídos todos os diferentes termos lingüísticos para as demais variáveis.

6 Apurou-se, também, a avaliação para os dados de referência de CA e de \% de carne segundo o "estado da arte" de 1985, 1995 e 2005 (conforme percepção do especialista E3), e de 1995 e 2005 (conforme o especialista E4). Os referenciais de avaliação tendem a ficar mais exigentes com a melhoria da tecnologia. 
FIGURA 4- REPRESENTAÇÃO DOS CONJUNTOS FUZZY PARA A VARIÁVEL \% CARNE

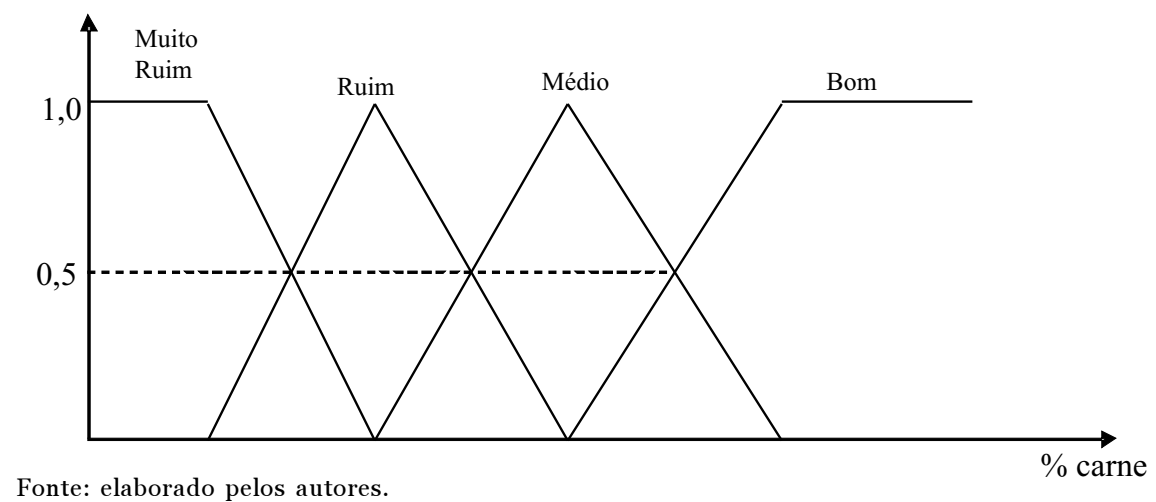

\subsubsection{Qualidade da carcaça}

A partir dos termos lingüísticos, foram arbitradas 16 regras, que compõem a base de regras para a inferência sobre a Qualidade da Carcaça, como mostra o Quadro 1. Para a inferência a respeito da variável conseqüente Qualidade da Carcaça, lêem-se as regras da seguinte forma:

$\boldsymbol{R}^{(a)}$ : Se o Percentual de Carne é $A_{i} \boldsymbol{E}$ a Espessura de

Toucinho é $B_{i}$

Então a Qualidade da Carcaça é $C_{i}$

Sendo $l=1, \ldots, 16, A_{i}, B_{i}$ e $C_{i}$ representam os conjuntos fuzzy referentes aos termos lingüísticos "bom", "médio", "ruim" ou "muito ruim", para $i=1,2,3,4$, respectivamente.

O antecedente da regra "Se o Percentual de Carne é $A_{i} \boldsymbol{E}$ a Espessura de Toucinho é $B_{i}$ ” corresponde ao mecanismo de fuzzyficação dado pelo conectivo lógico $\boldsymbol{E}$, o qual representa a interseção. Como descrito anteriormente, a norma triangular associada à intersecção é o operador min, ou seja, o menor dos graus de pertinência de Percentual de Carne (\% de carne) e Espessura de Toucinho (ET). Assim, o conseqüente da regra "Então a Qualidade da Carcaça é $C_{i}$ " é inferido para a Qualidade da Carcaça (QC).

A partir da opinião de cada um dos especialistas (E1, E2, E3, E4) e dos dados de referência (RF) representativos das variáveis antecedentes 
ROHENKOHL, J. \& MARTINELLI, O. \& BALLINI, R. Inovação em produtos agroalimentares...

QUADRO 1- BASE DE REGRAS PARA A QUALIDADE DE CARCAÇA (QC)

\begin{tabular}{|c|c|c|}
\hline \% carne & ET & QC \\
\hline Bom & Boa & Boa \\
\hline Bom & Média & Boa \\
\hline Bom & Ruim & Média \\
\hline Média & Boa & Boa \\
\hline Média & Média & Média \\
\hline Média & Ruim & Ruim \\
\hline Ruim & Boa & Média \\
\hline Ruim & Média & Ruim \\
\hline Ruim & Ruim & Ruim \\
\hline Muito Ruim & Muito Ruim & Muito Ruim \\
\hline Muito Ruim & Ruim & Muito Ruim \\
\hline Muito Ruim & Média & Ruim \\
\hline Muito Ruim & Boa & Média \\
\hline Ruim & Muito Ruim & Muito Ruim \\
\hline Média & Muito Ruim & Ruim \\
\hline Bom & Muito Ruim & Média \\
\hline
\end{tabular}

Fonte: elaborado pelos autores.

"\%de carne" e "ET" para os anos 2000/20047, 1995 e 1985, obtém-se as pertinências $(m)$ dos valores lingüísticos (bom, médio, ruim, muito ruim) definidores dos conjuntos fuzzy (Tabela 1). A aplicação da base de regras na Tabela 1 para o processamento das interseções permite inferir a Qualidade da Carcaça segundo a opinião de cada especialista para o valor de referência (RF) de cada ano.

7 Para o percentual de carne na carcaça a série utilizada apresenta dados apenas até o ano de 2000. 
ROHENKOHL, J. \& MARTINELLI, O. \& BALLINI, R. Inovação em produtos agroalimentares...

TABELA 1- DADOS DE REFERÊNCIA E PERTINÊNCIA AOS CONJUNTOS FUZZY

\begin{tabular}{clll}
\hline 2000/04 & RF: $57,5 \%$ carne & RF: 8,16 ET & QC \\
\hline E1 & $=0,5$ bom & $=0,625$ boa & $=0,5$ boa \\
E2 & $=0,83$ médio & $=0,54$ média & $=0,54$ média \\
E3 & $=0,83$ médio & $=0,33$ boa & $=0,33$ boa \\
E4 & $=0,5$ bom & $=0,07$ boa & $=0,07$ boa \\
\hline 1995 & RF: $54 \%$ carne & RF: $14,3 \mathrm{ET}$ & $\mathrm{QC}$ \\
\hline E1 & $=0,35$ ruim & $=0,37$ muito ruim & $=0,35$ muito ruim \\
E2 & $=0,7$ médio & $=0,6$ média & $=0,6$ média \\
E3 & $=0,7$ médio & $=1$ média & $=0,7$ média \\
E4 & $=0,5$ ruim & $=0,95$ média & $=0,5$ ruim \\
\hline 1985 & RF: $50 \%$ carne & RF: 21,9 ET & QC \\
\hline E1 & $=0,5$ muito ruim & $=0,35$ muito ruim & $=0,35$ muito ruim \\
E2 & $=0,5$ ruim & $=0,20$ muito ruim & $=0,20$ muito ruim \\
E3 & $=0,58$ ruim & $=0,51$ ruim & $=0,51$ ruim \\
E4 & $=0,5$ ruim & $=0,9$ muito ruim & $=0,5$ muito ruim \\
\hline
\end{tabular}

Fonte: elaborado pelos autores.

As diferentes opiniões dos especialistas $E_{i}(i=1,2,3,4)$ para um determinado ano $(1985,1995,2000 / 04)$ são agregadas por união efetuada com o operador max de forma a obter uma representação sintética de todas as opiniões coletadas para um determinado ano, conforme ilustra a Figura 5 .

A etapa de defuzzyficação das áreas (ou conjuntos fuzzy), representadas na Figura 5, é visualizada na segunda linha da Tabela 4 (p. 17) e facilita a comparação e medição da evolução da Qualidade da Carcaça no tempo. 
ROHENKOHL, J. \& MARTINELLI, O. \& BALLINI, R. Inovação em produtos agroalimentares...

FIGURA 5- INFERÊNCIA PARA A QUALIDADE DA CARCAÇA NOS ANOS DE 1985,1995 E 2000/04
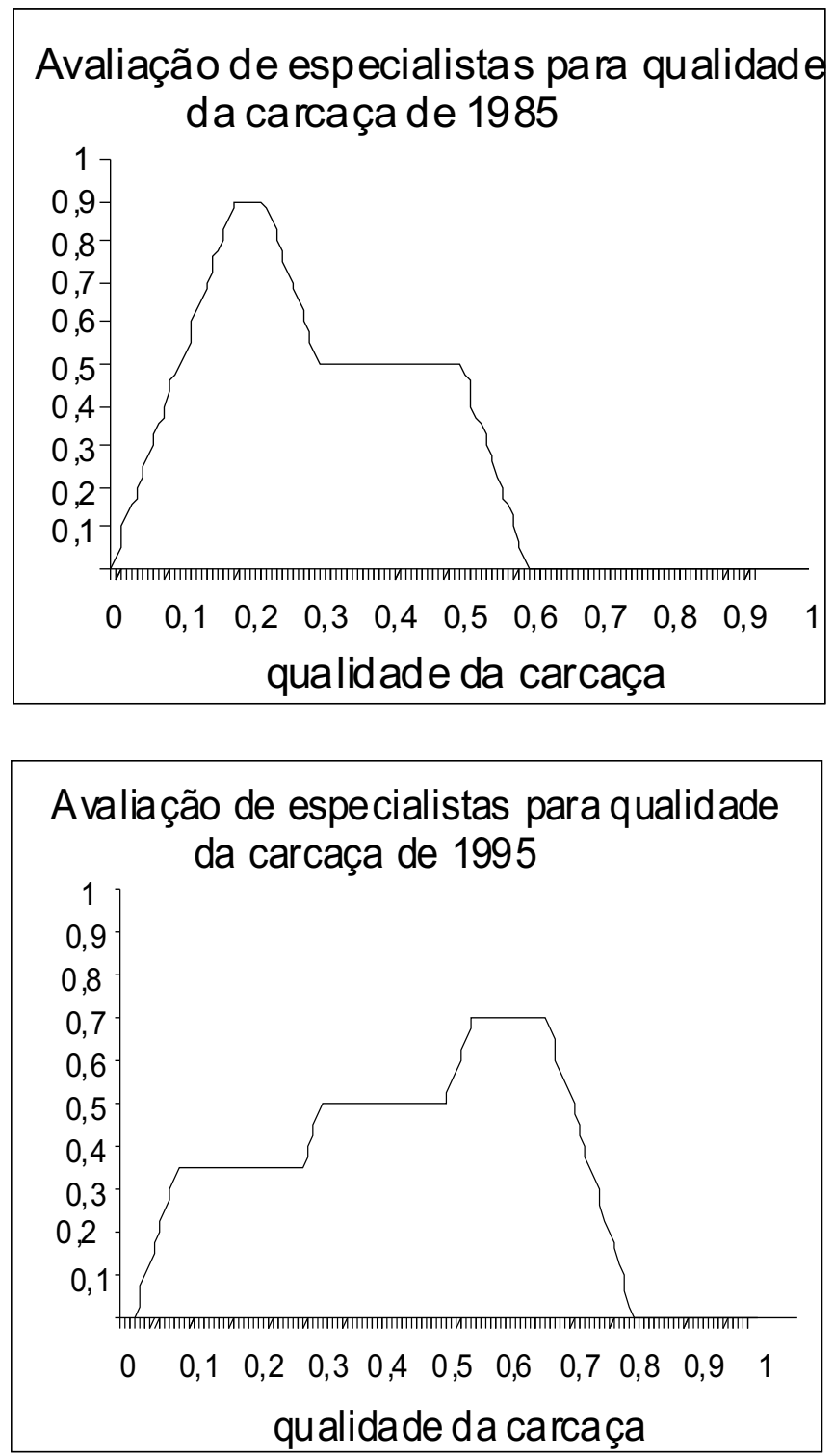


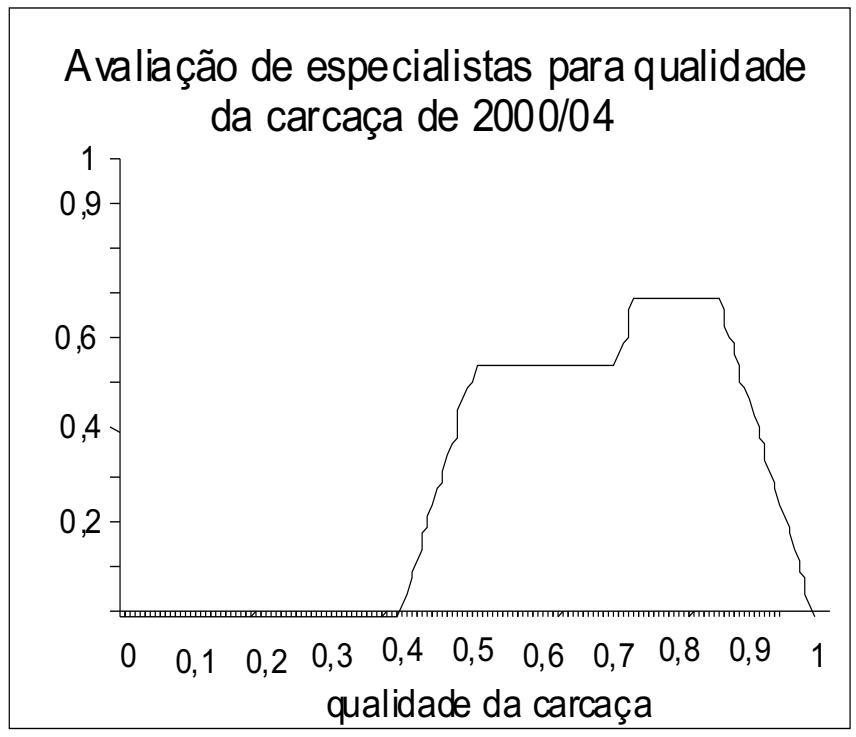

Fonte: Elaborado pelos autores.

\subsubsection{Produtividade}

Para obter um conjunto que retratasse a Produtividade, procedeu-se de maneira similar à empreendida para a Qualidade de Carcaça. A base de regras, as pertinências utilizadas e os resultados são apresentados a seguir. Neste caso, as 16 regras que compõem a base de regras são constituídas pelos antecedentes "leitões nascidos por parto" (LP) e "conversão alimentar" (CA) e a variável conseqüente é representada pela Produtividade. O Quadro 2 apresenta a base de regras utilizada para inferir sobre a Produtividade.

A Tabela 2 apresenta os valores de "leitões nascidos por parto" (LP) e "conversão alimentar" (CA) referentes a 2004, 1995 e 1985, as pertinências aos valores lingüísticos definidores dos conjuntos construídos a partir da opinião de cada um dos especialistas (E1, E2, E3, E4) e do conjunto conseqüente Produtividade.

A Figura 6 traz os resultados da agregação sobre a produtividade dos suínos para esses anos, com base nos valores de pertinência apresentados na Tabela 2.

A defuzzyficação da variável Produtividade é apresentada na linha 3 da Tabela 4 (p.133). 
ROHENKOHL, J. \& MARTINELLI, O. \& BALLINI, R. Inovação em produtos agroalimentares...

QUADRO 2- BASE DE REGRAS PARA A PRODUTIVIDADE

\begin{tabular}{|c|c|c|}
\hline LP & CA & Produtividade \\
\hline Muito baixa & Muito ruim & Muito baixa \\
\hline Muito baixa & Ruim & Muito baixa \\
\hline Muito baixa & Média & Muito baixa \\
\hline Muito baixa & Boa & Baixa \\
\hline Baixa & Muito ruim & Muito baixa \\
\hline Média & Muito ruim & Muito baixa \\
\hline Alta & Muito ruim & Baixa \\
\hline Baixa & Ruim & Baixa \\
\hline Baixa & Média & Baixa \\
\hline Baixa & Boa & Média \\
\hline Média & Ruim & Baixa \\
\hline Média & Média & Média \\
\hline Média & Boa & Alta \\
\hline Alta & Ruim & Média \\
\hline Alta & Média & Média \\
\hline Alta & Boa & Alta \\
\hline
\end{tabular}

Fonte: Elaborado pelos autores.

TABELA 2- VALORES DE REFERÊNCIA E PERTINÊNCIA AOS CONJUNTOS FUZZY

\begin{tabular}{|c|c|c|c|}
\hline 2004 & $\begin{array}{l}\text { RF: } 11,87 \text { LP } \\
\text { (prolificidade) }\end{array}$ & $\begin{array}{c}\text { RF: } 2,33 \mathrm{Kg} \text { ração/ Kg } \\
\text { porco vivo (CA) }\end{array}$ & Produtividade \\
\hline E1 & $\mathrm{A}=0,15$ alta & $\mathrm{A}=0,75$ média & $\mathrm{A}=0,15$ média \\
\hline E3 & $\mathrm{A}=0,75$ média & $\mathrm{A}=1 \mathrm{boa}$ & $\mathrm{A}=0,75$ alta \\
\hline $\mathrm{E} 4$ & $\mathrm{~A}=0,7$ média & $\mathrm{A}=0,75$ boa & $\mathrm{A}=0,7$ alta \\
\hline 1995 & $\begin{array}{l}\text { RF: } 10,55 \mathrm{LP} \\
\text { (prolificidade) }\end{array}$ & $\begin{array}{l}\mathrm{RF}: 2,53 \mathrm{Kg} \text { ração/ Kg } \\
\text { porco vivo (CA) }\end{array}$ & Produtividade \\
\hline E1 & $\mathrm{A}=0,55$ alta & $\mathrm{A}=0,62$ ruim & $\mathrm{A}=0,55$ média \\
\hline E3 & $\mathrm{A}=0,55$ baixa & $\mathrm{A}=0,75$ ruim & $\mathrm{A}=0,55$ baixa \\
\hline $\mathrm{E}_{4}$ & $\mathrm{~A}=0,1$ muito baixa & $\mathrm{A}=0,9$ ruim & $\mathrm{A}=0,1$ muito baixa \\
\hline 1985 & $\begin{array}{l}\text { RF: } 10,17 \text { LP } \\
\text { (prolificidade) }\end{array}$ & $\begin{array}{l}\mathrm{RF}: 2,68 \mathrm{Kg} \text { ração/ Kg } \\
\text { porco vivo (CA) }\end{array}$ & Produtividade \\
\hline E1 & $\mathrm{A}=0,8$ média & $\mathrm{A}=0,62$ ruim & $A=0,62$ baixa \\
\hline E3 & $\mathrm{A}=0,15$ baixa & $\mathrm{A}=0,75$ muito ruim & $\mathrm{A}=0,15$ muito baixa \\
\hline
\end{tabular}

Fonte: Elaborado pelos autores. 
ROHENKOHL, J. \& MARTINELLI, O. \& BALLINI, R. Inovação em produtos agroalimentares...

FIGURA 6- INFERÊNCIA DA PRODUTIVIDADE DE SUÍNOS PARA 1985, 1995 E 2004
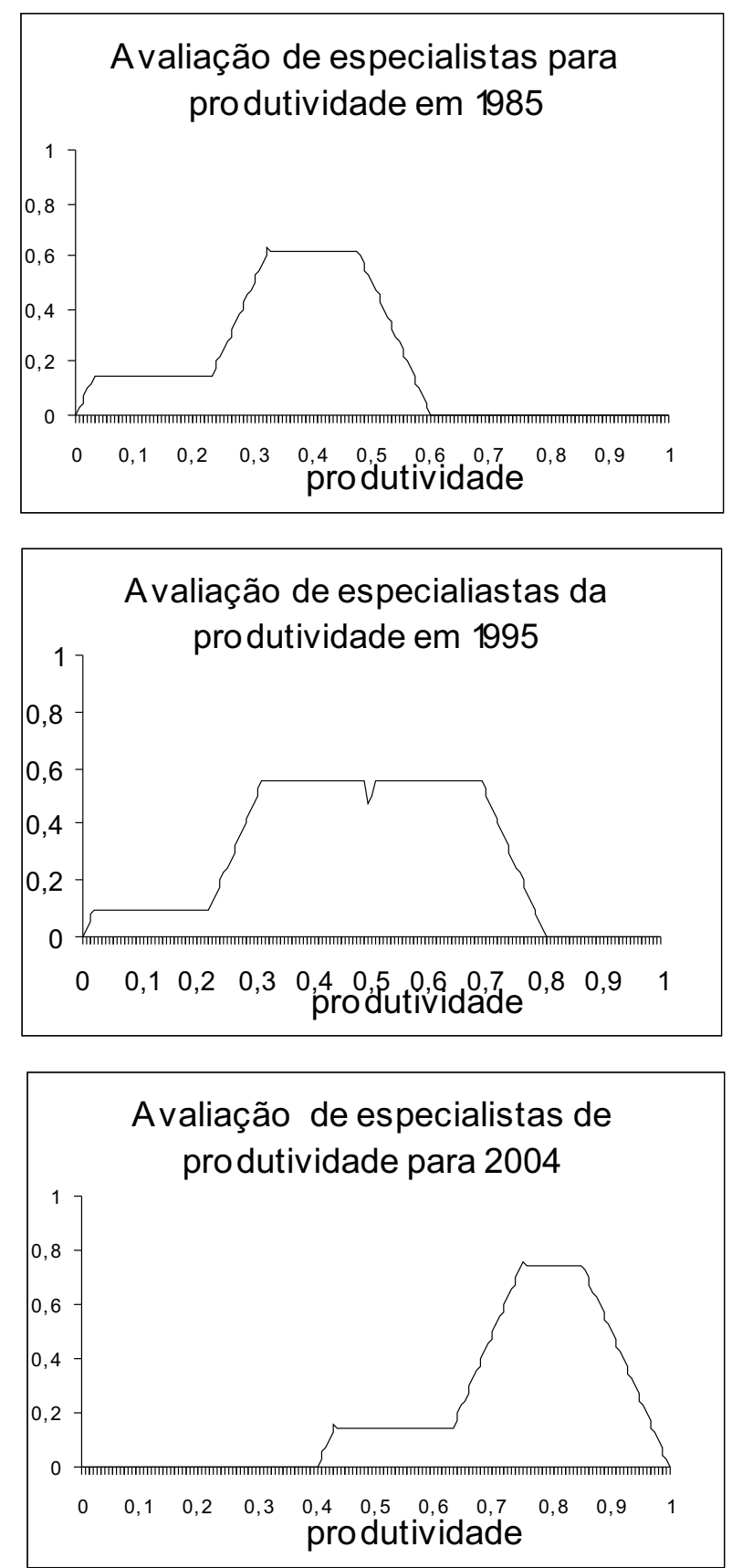

Fonte: Elaborado pelos autores. 


\subsubsection{Qualidade da carne}

A preocupação com a cor e a capacidade de retenção de água da carne é evidente nas firmas e na literatura especializada desde a segunda metade dos anos 90 do século XX. No entanto, não se encontrou série histórica nacional para utilização. Há uma associação entre o padrão japonês de 6 cores da carne suína, em um gradiente que inicia na branca pálida e vai até a cor vermelho escuro, e a classificação da carne em um padrão de 4 classes que informa a coloração combinada com a maciez e a retenção de água. As classes são: Pale, Soft and Exudative (PSE); Red, Soft and Exudative (RSE); Red, Firm and Non-Exudative (RFN); and Dark, Firm and Dry (DFD). A carne PSE é indesejada devido à perda de água e palidez. A DFD tende a ser dura e seca. A RSE é um intermediário e a RFN costuma ser a almejada pela indústria.

A partir da opinião dos especialistas (E2, E3 e E4) obteve-se uma associação entre a cor 4 da carne suína no padrão japonês e as classes que sintetizam a avaliação de cor, retenção de água e maciez para a Qualidade da Carne, apresentada na Tabela 3.

TABELA 3- PERTINÊNCIA DA COR 4 À CLASSIFICAÇÃO DE QUALIDADE PSE, RSE, RFN E DFD

\begin{tabular}{ccccc}
\hline Classe & PSE & RSE & RFN & DFD \\
\hline E2 & $\mathrm{u}_{\mathrm{A}}=\mathrm{O}$ & $\mathrm{u}_{\mathrm{A}}=\mathrm{O}$ & $\mathrm{u}_{\mathrm{A}}=\mathrm{O}$ & $\mathrm{u}_{\mathrm{A}}=0,8$ \\
$\mathrm{E} 3$ & $\mathrm{u}_{\mathrm{A}}=\mathrm{O}$ & $\mathrm{u}_{\mathrm{A}}=\mathrm{O}$ & $\mathrm{u}_{\mathrm{A}}=1$ & $\mathrm{u}_{\mathrm{A}}=0$ \\
$\mathrm{E} 4$ & $\mathrm{u}_{\mathrm{A}}=\mathrm{o}$ & $\mathrm{u}_{\mathrm{A}}=\mathrm{O}$ & $\mathrm{u}_{\mathrm{A}}=1$ & $\mathrm{u}_{\mathrm{A}}=0$ \\
\hline
\end{tabular}

Fonte: Elaborado pelos autores.

Uma vez estabelecida uma relação entre a cor 4 e a classificação PSE, RSE, RFN e DFD, monta-se uma base de regras, composta por 4 regras, para inferir a respeito da variável Qualidade da Carne a partir da intersecção entre a Classe e o Limite Máximo de Resíduos (LMR) estabelecido para diferentes substâncias (medicamentos, promotores de crescimento) utilizadas na criação dos animais conforme padrões do Codex Alimentarius (Quadro 3). O LMR é proposto como um conjunto binário, com a pertinência 1 para níveis de resíduos aceitáveis e o para níveis inaceitáveis. Montou-se uma inferência ilustrativa para uma amostra de carne da cor 4 do padrão japonês, combinada com níveis de resíduos 
ROHENKOHL, J. \& MARTINELLI, O. \& BALLINI, R. Inovação em produtos agroalimentares...

nos tecidos (LMR), na qual os LMR são supostos como aceitáveis, cujo resultado é apresentado na Figura 7. A variável base da Qualidade da Carne, de mesmo nome, varia de o a 1.

Usando o método do centro de gravidade (Pedrycz \& Gomide 1998) para a defuzzyficação das variáveis conseqüentes Qualidade de Carcaça, Produtividade e Qualidade da Carne, pode-se observar a transformação dos porcos e de sua carcaça ao longo dos anos, como mostra a Tabela 4.

QUADRO 3- BASE DE REGRAS PARA A QUALIDADE DA CARNE

\begin{tabular}{|c|c|c|}
\hline Classe & LMR & $\begin{array}{c}\text { Qualidade de } \\
\text { Carne }\end{array}$ \\
\hline PSE & Aceitável & Muito ruim \\
\hline RSE & Aceitável & Média \\
\hline RFN & Aceitável & Boa \\
\hline DFD & Aceitável & Ruim \\
\hline
\end{tabular}

Fonte: Elaborado pelos autores.

FIGURA 7- INFERÊNCIA PARA A QUALIDADE DA CARNE

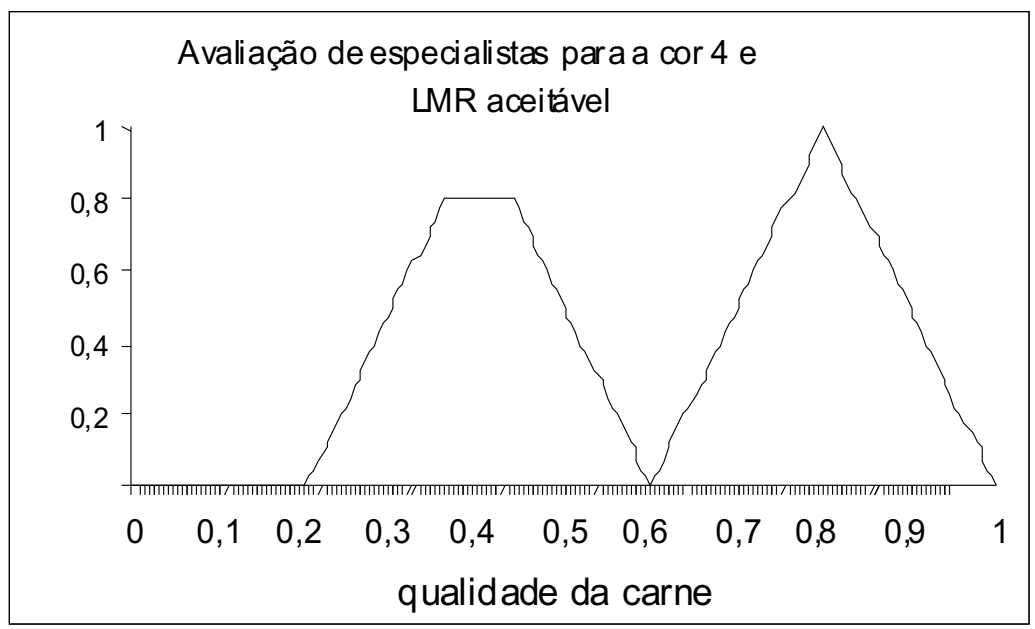

Fonte: Elaborado pelos autores. 
ROHENKOHL, J. \& MARTINELLI, O. \& BALLINI, R. Inovação em produtos agroalimentares...

TABELA 4- VALORES DA DEFUZZYFICAÇÃO DOS RESULTADOS DAS INFERÊNCIAS

\begin{tabular}{cccc}
\hline Ano & 1985 & 1995 & $2000 / 2004$ \\
\hline Qualidade de Carcaça & 0,12 & 0,44 & 0,70 \\
Produtividade & 0,36 & 0,47 & 0,76 \\
$\begin{array}{c}\text { Qualidade de Carne } \\
\text { (cor 4, LMR aceitável) }\end{array}$ & - & - & 0,60 \\
\hline
\end{tabular}

Fonte: Elaborado pelos autores.

\section{3 Índice de adequação ao esperado para 2010}

Um índice de adequação ao esperado para 2010 é apresentado a seguir. Este índice complementa a observação da transformação do animal e da carcaça no tempo e projeta valores para as variáveis "conversão alimentar", "percentual de carne na carcaça, "número de leitões nascidos por parto" e "espessura de toucinho". A confiança declarada pelos especialistas no valor esperado de uma variável em 2010 é interpretada como um valor de pertinência ao conjunto "Esperado", caso persista a trajetória tecnológica atual.

O índice de adequação ao esperado para 2010, adaptado da proposição de Guerrero et al. (1999), é representado por $K$ e estabelecido da seguinte forma:

- se a pertinência da média da variável $Y$ no ano $X$ ao conjunto Esperado (E) para 2010, é igual ou maior do que a confiança dos especialistas na expectativa de média de $Y$ para 2010 , então $K=1$;

- se a pertinência da média da variável $Y$ para o ano $X$ é menor que a confiança (ou pertinência) ao esperado como média de $Y$ em 2010, então, $K=1-\mu_{E} Y_{2010}+\mu_{E} Y_{\text {AnoX }}$.

O cálculo da pertinência ao conjunto "Esperado para 2010" baseou-se em funções triangulares. Como ficou evidente nas entrevistas que os especialistas possuem "modelos de cognição" semelhantes entre si, o estabelecimento do segmento de reta calculado como ascendente ou descendente considerou o contexto das respostas. Utilizou-se sempre um valor classificado no intervalo associado ao conjunto "baixo", "ruim", "muito baixo" ou "muito ruim" nas respostas dos especialistas aos padrões de 2005, como de pertinência o. Este valor correspondente à 
pertinência o foi combinado com a confiança dos especialistas ao "Esperado para 2010" a fim de estabelecer um segmento de reta do conjunto triangular fuzzy centralizado representando a expectativa para 2010. A partir disto foi definido um ponto de pertinência 1 de forma a obter um conjunto no qual estivessem contidas todas as opiniões com os respectivos graus de confiança atribuídos pelos especialistas.

\subsubsection{Variável Percentual de Carne na Carcaça}

A primeira linha da Tabela 5 apresenta o percentual de carne que pelo menos um dos especialistas espera que seja alcançado. Nas demais linhas constam os valores da confiança depositados nas expectativas. Para o estabelecimento da expectativa considerou-se o percentual de $52 \%$ de carne na carcaça como de pertinência o(zero) ao esperado em

TABELA 5- VALOR DE PERCENTUAL DE CARNE ESPERADO EM 2010 E CONFIANÇA ATRIBUÍDA PELOS ESPECIALISTAS $\left(M_{E} \% 2010\right)$

\begin{tabular}{cccc}
\hline $\begin{array}{c}\text { Percentual } \\
\text { de carne }\end{array}$ & $59 \%$ & $60 \%$ & $62 \%$ \\
E1 & - & - & 0,7 \\
E2 & - & - & 0,8 \\
E3 & - & 0,8 & - \\
E4 & $0,7^{8}$ & - & - \\
\hline
\end{tabular}

Fonte: Elaborado pelos autores.

2010 e $62 \%$ como de pertinência igual a 1 . A média de percentual de carne do ano de 2000 foi 57,5. Assim, a pertinência ao conjunto esperado para 2010 é dada por:

$$
\mu_{E} \% 200 O=\left(57,5^{-} 52\right) /(62-52)=5,5 / 10=0,55
$$

Procedeu-se de forma idêntica para os anos de 1995, 1990 e 1985, nos quais a média de percentual de carne forma 52,5 ; 50 e 48 , respectiva-

\footnotetext{
8 A resposta do Especialista 4 é emblemática do sentido do conjunto Esperado. Ele afirmou que $62 \%$ de carne na carcaça são biologicamente possíveis de obter-se, mas que há um trade-off entre percentual de carne na carcaça e aspectos de qualidade como gordura intramuscular e pH e que, portanto, espera que em 2010 seja alcançado o percentual de 59\%. A esta expectativa atribui a confiança de $0,7$.
} 
mente. Assim, para esses anos, as pertinências ao conjunto esperado para 2010 são:

$$
\begin{aligned}
& \mu_{E} \% 1995=(52,5-52) / 10=0,05 \\
& \mu_{E} \% 1990=(50-52) / 10=0,0 \\
& \mu_{E} \% 1985=(48-52) / 10=0,0
\end{aligned}
$$

As pertinências da média de percentual de carne de cada ano ao conjunto "Esperado para 2010" são utilizadas para calcular o índice de adequação à expectativa para 2010. Sendo $K \%$ o índice de adequação do percentual médio de carne observado em 2000 ao esperado para 2010, têm-se as seguintes regras:

$$
\begin{aligned}
& \text { Se } \mu_{E} \% 200 O \text { e" } \mu_{E} \% 201 O \text { Então } K \%=1 ; \\
& \text { Se } \mu_{E} \% 200 O<\mu_{E} \% 2010 \text { Então } K \%=1-\mu_{E} \% 201 O+\mu_{E} \% 2 O O O
\end{aligned}
$$

Como a maior confiança dos especialistas na média esperada para 2010 foi $m_{E} \% 2010=0,8$ e considerando o percentual médio de carne de 2000, o índice de adequação é dado por:

$$
K \%_{2000}=(1-0,8)+0,55=0,75
$$

Para os demais anos, têm-se:

$$
\begin{aligned}
& K \%_{1995}=(1-0,8)+0,05=0,25 \\
& K \%_{1990}=(1-0,8)+0=0,2 \\
& K \%_{1985}=(1-0,8)+0=0,2
\end{aligned}
$$

O índice $K \%=$ o,2 para os anos de 1990 e 1985 , em que $m_{E} \%=$ o, é a medida da desconfiança na expectativa e decorre da diferença entre a certeza ou confiança absoluta $\left(m_{E} \%=1,0\right)$ e a maior confiança nas expectativas para 2010, que foi de $0,8(1-0,8=0,2)$. 
ROHENKOHL, J. \& MARTINELLI, O. \& BALLINI, R. Inovação em produtos agroalimentares...

\subsubsection{Variável Espessura de Toucinho (ET)}

Para o estabelecimento do conjunto esperado considerou-se a ET de $28 \mathrm{~mm}$ com a pertinência igual a zero e oito milímetros com pertinência igual a um. A primeira linha da Tabela 6 apresenta a espessura de toucinho que pelo menos um dos especialistas espera que seja alcançada em 2010. Nas demais linhas constam os valores da confiança depositada nas expectativas.

TABELA 6- ESPESSURA DE TOUCINHO ESPERADA EM 2010 E CONFIANÇA ATRIBUÍDA PELOS ESPECIALISTAS $\left(M_{E} E T 2010\right)$

\begin{tabular}{lccc}
\hline ET & $8 \mathrm{~mm}$ & $10 \mathrm{~mm}$ & $12 \mathrm{~mm}$ \\
\hline E1 & - & 0,7 & - \\
E2 & 0,8 & - & - \\
E3 & 1 & - & - \\
E4 & - & - & 0,8 \\
\hline
\end{tabular}

Fonte: Elaborado pelos autores.

As pertinências das médias da variável "espessura de toucinho" dos anos de 1985 até 2004 ao conjunto esperado para 2010 são dadas por:

$$
\begin{aligned}
& \mu_{E} E T 1985=(21,9-28) /(8-28)=0,305 \\
& \mu_{E} E T 199 O=(18,4-28) /(8-28)=0,48 \\
& \mu_{E} E T 1995=(14,3-28) /(8-28)=0,685 \\
& \mu_{E} E T 2 O 0 O=(11,37-28) /(8-28)=0,83 \\
& \mu_{E} E T 2004=(8,16-28) /(8-28)=0,99 .
\end{aligned}
$$

As pertinências da média de ET de cada ano ao conjunto esperado para 2010 são agora utilizadas para calcular o índice de adequação à expectativa para 2010. Sendo KET o índice de adequação da ET média observada em 2004 ao esperado para 2010, tem-se9:

Se $\mu_{E} E T 2 O O 4$ e" $\mu_{E} E T 2 O 1 O$ Então $K E T=1 ;$

9 A maior confiança $m_{E} E T 2010$ dos especialistas foi 1 - usado na elaboração do índice $K E T$. 
ROHENKOHL, J. \& MARTINELLI, O. \& BALLINI, R. Inovação em produtos agroalimentares...

Se $m_{E} E T 2 O O 4<m_{E} E T 2 O 1 O$ Então $K E T=1-m_{E} E T 2 O 1 O+m_{E} E T 2 O O 4$

Em 2004, o índice de adequação ao esperado para 2010 é:

$$
K E T_{2004}=(1-1)+0,99=0,99 \text {. }
$$

Para os demais anos, procedeu-se da mesma forma e obteve-se o seguinte:

$$
\begin{aligned}
& K E T_{2000}=1-1+0,83=0,83 \\
& K E T_{1995}=1-1+0,685=0,685 \\
& K E T_{1990}=1-1+0,48=0,48 \\
& K E T_{1985}=1-1+0,305=0,305 .
\end{aligned}
$$

\subsubsection{Média de Leitões Nascidos Por Parto (LP)}

Para o conjunto que retrata as expectativas em relação à média de leitões nascidos por parto, considerou-se 3,5 leitões nascidos como de pertinência igual a zero e treze e meio com pertinência 1. A primeira linha da Tabela 7 apresenta a LP que pelo menos um dos especialistas espera que seja alcançada. Nas demais linhas constam valores relativos à confiança de cada especialista depositada na própria expectativa.

TABELA 7- VALOR DO LP ESPERADO EM 2010 E CONFIANÇA ATRIBUÍDA PELOS ESPECIALISTAS $\left(M_{E} L P 2010\right)$

\begin{tabular}{ccc}
\hline LP & $\mathbf{1 2 , 5}$ & $\mathbf{1 3}$ \\
\hline E1 & 0,8 & - \\
E3 & - & 0,9 \\
E4 & 0,9 & - \\
\hline
\end{tabular}

Fonte: Elaborado pelos autores.

A pertinência das médias de LP dos anos de 1985 até 2004 ao conjunto esperado para 2010 é dada por:

$$
\mu_{E} L P 1985=(9,65-3,5) /\left(13,5^{-}-3,5\right)=0,615
$$


ROHENKOHL, J. \& MARTINELLI, O. \& BALLINI, R. Inovação em produtos agroalimentares...

$$
\begin{aligned}
& \mu_{E} L P 1990=(10,05-3,5) /(10)=0,655 \\
& \mu_{E} L P 1995=(10,55-3,5) /(10)=0,705 \\
& \mu_{E} L P 200 O=(10,96-3,5) /(10)=0,75 \\
& \mu_{E} L P 2004=(11,87-3,5) /(10)=0,84 .
\end{aligned}
$$

O cálculo do índice de adequação da média de 2004 ao valor esperado para 2010 segue a regra ${ }^{10}$ :

$$
\begin{aligned}
& \text { Se } \mu_{E} L P 2004 \text { e" } \mu_{E} L P 2 O 1 O \text { Então } K L P=1 ; \\
& \text { Se } \mu_{E} L P 2004<\mu_{E} L P 2 O 1 O \text { Então } K L P=1-\mu_{E} L P 2 O 1 O+ \\
& \mu_{E} L P 2 O O 4
\end{aligned}
$$

O cálculo do índice referente à média de 2004 é o seguinte:

$$
K L P_{2004}=1-0,9+0,84=0,94
$$

Procedeu-se de maneira análoga para os demais anos obtendo-se:

$$
\begin{aligned}
& K L P_{2000}=1-0,9+0,75=0,85 \\
& K L P_{1995}=1-0,9+0,705=0,805 \\
& K L P_{1990}=1-0,9+0,655=0,755 \\
& K L P_{1985}=1-0,9+0,615=0,715 .
\end{aligned}
$$

\subsubsection{Conversão Alimentar (CA)}

A primeira linha da Tabela 8 apresenta a CA que pelo menos um dos especialistas espera que seja alcançada. Nas demais linhas constam valores da confiança de cada especialista depositada na própria expectativa.

Na construção do conjunto retratando as expectativas em relação à CA considerou-se 3,8 Kgs de ração/ $\mathrm{Kg}$ de suíno como de pertinência igual a zero e dois quilos e trezentos de ração/ Kg de suíno com pertinência 1 . A pertinência das médias da variável "conversão alimentar" dos anos de 1985 até 2004 ao conjunto esperado para 2010 é apresentada abaixo.

10 A maior confiança $m_{E} L P 2010$ dos especialistas foi o,9 - usado na elaboração do índice $K L P$. 
ROHENKOHL, J. \& MARTINELLI, O. \& BALLINI, R. Inovação em produtos agroalimentares...

$$
\begin{aligned}
& \mu_{E} C A 1985=(2,65-3,8) /(2,3-3,8)=0,77 \\
& \mu_{E} C A 1990=(2,62-3,8) /(2,3-3,8)=0,79 \\
& \mu_{E} C A 1995=(2,53-3,8) /(2,3-3,8)=0,85 \\
& \mu_{E} C A 2 O O O=(2,29-0,8) /(2,3-0,8)=0,99 \\
& \mu_{E} C A 2004=(2,33-3,8) /(2,3-3,8)=0,98
\end{aligned}
$$

TABELA 8- VALOR DE CONVERSÃO ALIMENTAR ESPERADA EM 2010 E CONFIANÇA ATRIBUÍDA PELOS ESPECIALISTAS $\left(M_{E} C A 2010\right)$

\begin{tabular}{lcc}
\hline CA & 2,3 & 2 \\
\hline E1 & - & 0,8 \\
E3 & 1 & - \\
E4 & - & 0,8 \\
\hline
\end{tabular}

Fonte: Elaborado pelos autores.

As pertinências da média de CA de cada ano ao conjunto esperado para 2010 são utilizadas para calcular o índice de adequação a expectativa para 2010 conforme a regra ${ }^{11}$ :

\section{Se $\mu_{E} C A 2004$ e" $\mu_{E} C A 201 O$ Então $K C A=1$;}

Se $\mu_{E} C A 2004<\mu_{E} C A 201 O$ Então $K C A=1-\mu_{E} C A 2 O 1 O+\mu_{E} C A 2 O O 4$

O índice de adequação da média de CA de 2004 é apresentado logo a seguir.

$$
K C A_{2004}=(1-1)+0,98=0,98
$$

Para os demais anos os valores são:

$$
\begin{aligned}
& K C A_{2000}=(1-1)+0,99=0,99 \\
& K C A_{1995}=(1-1)+0,85=0,85 \\
& K C A_{1990}=(1-1)+0,79=0,79 \\
& K C A_{1985}=(1-1)+0,77=0,77 .
\end{aligned}
$$

11 A maior confiança $m_{E} C A 2010$ dos especialistas foi 1- usado na elaboração do índice $K C A$. 
Na Tabela 9 estão os índices de adequação aos valores esperados para 2010. Eles ilustram o que é esperado para 2010 conforme a opinião dos especialistas consultados.

\begin{tabular}{clll} 
TABELA 9- ÍNDICES DE ADEQUAÇÃO AO ESPERADO PARA 2010 \\
\hline $2000 / 04$ & RF: $57,5 \%$ carne & RF: 8,16 ET & QC \\
\hline E1 & $=0,5$ bom & $=0,625$ boa & $=0,5$ boa \\
E2 & $=0,83$ médio & $=0,54$ média & $=0,54$ média \\
E3 & $=0,83$ médio & $=0,33$ boa & $=0,33$ boa \\
E4 & $=0,5$ bom & $=0,07$ boa & $=0,07$ boa \\
\hline $1995 / 96$ & RF: $54 \%$ carne & RF: 14,3 ET & QC \\
\hline E1 & $=0,35$ ruim & $=0,37$ muito ruim & $=0,35$ muito ruim \\
E2 & $=0,7$ médio & $=0,6$ média & $=0,6$ média \\
E3 & $=0,7$ médio & $=1$ média & $=0,7$ média \\
E4 & $=0,5$ ruim & $=0,95$ média & $=0,5$ ruim \\
\hline 1985 & RF: $50 \%$ carne & RF: 21,9 ET & QC \\
\hline E1 & $=0,5$ muito ruim & $=0,35$ muito ruim & $=0,35$ muito ruim \\
E2 & $=0,5$ ruim & $=0,20$ muito ruim & $=0,20$ muito ruim \\
E3 & $=0,58$ ruim & $=0,51$ ruim & $=0,51$ ruim \\
E4 & $=0,5$ ruim & $=0,9$ muito ruim & $=0,5$ muito ruim \\
\hline
\end{tabular}

Fonte: Elaborado pelos autores.

\section{Conclusões}

A realidade rica e até certo ponto turva que emerge dos estudos tecnológicos e institucionais exige instrumentais de apoio talhados para captá-la e ordená-la de forma lógica, facilitando tomar ciência das situações estudadas. A teoria dos conjuntos fuzzy permitiu evidenciar que há mais do que transformações de produtividade ocorrendo nos porcos e na carne suína e que produtividade e qualidade podem ser compostas para retratar simultaneamente diversos aspectos de um produto. Com ela, mesmo que a evidência inicial para a construção de um argumento seja nebulosa e expressa de forma imprecisa e verbalmente pelos sujeitos implicados nas tarefas de mudança tecnológica, é possível alcançar resultados relevantes. O modelo fuzzy utilizado ${ }^{12}$ oportunizou a ilustra-

\footnotetext{
12 Para a ilustração da transformação no tempo e da projeção de expectativas os procedimentos adotados foram suficientes. Não se pretendeu com as inferências, nem com o índice de adequação, obter representações definitivas. A medição efetuada por meio da teoria dos conjuntos fuzzy e referenciada no "estado de arte" tecnológico de 2005 é passível de revisão à medida que a tecnologia e o conhecimento alterem-se ao longo do tempo, mantendo na análise um aspecto complexo e fundamental da evolução tecnológica que é a transformação do produto simultânea à modificação das referências para avaliá-lo.
} 
ção da transformação de produtividade e de qualidade dos animais e da carne sem negar a evolução dos padrões de interpretação/cognição presentes na avaliação da diferenciação e da inovação dos produtos.

Observou-se uma transformação dos animais, da carcaça e da carne ao longo do tempo. Os suínos e a sua carne não podem ser tratados como commodities, a variação qualitativa impede que eles sejam diretamente comparados no tempo sem as devidas qualificações. Isso sugere, também, que a regra de formação de preço desses produtos no mercado pode estar incorporando as diferenciações qualitativas. As análises do preço da carne e dos animais serão mais precisas se considerarem esses aspectos.

Tendo como horizonte o ano de 2010, há indicações de que nas variáveis "espessura de toucinho" e "conversão alimentar" chegou-se, em 2004, praticamente ao limite do que especialistas consultados esperam que seja alcançado. Há uma sinalização de exaustão do potencial da trajetória desenvolvida na década de 1980 e que privilegia a quantidade de carne na carcaça. Há uma abertura do leque de atributos explorados tecnológica e comercialmente, lançando outra trajetória calcada no trade-off quantidade frente à qualidade da carne. Mais do que isto, inovações futuras podem ser implementadas com a exploração de outros atributos como o bem-estar dos animais e a resistência dos mesmos a doenças. Uma verificação mais aprofundada deste aspecto requer entrevistas com um maior número de especialistas.

\section{Referências}

ANDERSEN, H.J. (2000). "What is pork quality?" In WENK, Caspar. Quality of meat and fat in pigs as affected by genetics and nutrition. Zurich: European Association for Animal Production.

BOJADZIEV, G. \& BOJADZIEV, M (1995). Fuzzy sets, fuzzy logic, applications. Singapure: World Scientific Publishers Co. Pte. Ltd..

CARLSSON, B. \& STANKIEWICZ, R. (1991). "On the nature, function and composition of technological systems”. Journal of Evolutionary Economics 1:93-118.

CARLSSON, B \& JACOBSSON, S. \& HOLMÉN, M. \& RICKNE, A. (1999). "Innovations systems: analytical and methodological issues". URL: http:/ /www.druid.dk/conf-papers-attach/crlsson.pdf. Acesso em: 25 de maio de 2006.

CARLSSON, B. \& ELIASSON, G. (2003). "Industrial dynamic and endogenous growth". Industry and Innovation 10 (4):435-55.

CHEVASSUS-LOZZA, E. \& GALLEZOT, J. (1995). "La différenciation des produits dans la compétitivité: le cas de l’agriculture et de l`agro- 
alimentaire français". In: NICOLAS, F. \& VALCHESCHINI, E. (eds). Agroalimentaire: une économie de la qualité. Paris: INRA Economica, pp. 25363 .

DOSI, G. (1982). "Technological paradigms and technological trajectories". Research Policy 11:147-62.

EYMARD-DUVERNAY, F. (1989). "Conventions de qualité et formes de coordination". Revue de économique 2: 329-59.

EYMARD-DUVERNAY, F. (1995). "La négociation de la qualité". In NICOLAS, F. \& VALCHESCHINI, E. (eds). Agro-alimentaire: une économie de la qualité. Paris: INRA Economica, pp. 39-48.

FÁVERO, J. A. \& GUIDONI, A. L. (2001). "Normatização e padronização da tipificação de carcaças de suínos no Brasil - aspectos positivos e restrições". II Conferência Internacional Virtual sobre Qualidade de Carne Suína.

GUERRERO, L. \& LAZZARI, L. \& MACHADO, E. (1999). "Hacia un cambio de paradigma en la investigación de mercado". Cuaderno $n^{\circ} 2$ CIMBAGE. Buenos Aires: Centro de Investigación en Metodologias Borrosas Aplicadas a la Gestión y Economía, Faculdade de Ciencias Econômicas.

PEDRYCZ, W. \& GOMIDE, F. (1998). An Introduction to Fuzzy Sets: Analysis and Design. Cambridge: MIT Press,

PESSANHA, L. \& WILKINSON, J. (2003). "Transgênicos provocam novo quadro regulatório e novas formas de coordenação do sistema agroalimentar". Cadernos de Ciência e Tecnologia 20(2): 263-303.

NELSON, R \& WINTER, S. (1977). "In search of a useful theory of innovation". Research Policy 6: 36-76.

ROHENKOHL, J. E. (2006). Configurações institucionais e ambiente seletivo: um estudo econômico das trajetórias de inovação em genética suína no Brasil. Porto Alegre: tese doutorado, Universidade Federal do Rio Grande do Sul, Programa de Desenvolvimento Rural, Faculdade de Ciências Econômicas.

ZADEH, L. A. (1987) [1965] "Fuzzy Sets". Information and Control 8:33853. Reimpresso in YAGER, R. \& OVCHINNIKOV, S \& TONG, R. \& NGUYEN, H. (orgs) Selected papers by L.A. Zadeh. New York: John Wiley and Sons.

ZADEH, L. A. (1987) [1975]. "The concept of a linguistic variable and its application to approximate reasoning". Part 1. Information Sciences 8: 199-249. Reimpresso in YAGER, R. \& OVCHINNIKOV, S \& TONG, R. \& NGUYEN, H. (orgs) Selected papers by L.A. Zadeh. New York: John Wiley and Sons.

Submissão: 11 de dezembro de 2007 Primeira resposta: 17 de fevereiro de 2008

Aceite: 19 de fevereiro de 2008 